\title{
The Effect of Beam Oscillation Rate on Al Evaporation from a Ti-6Al-4V Alloy in the Electron Beam Melting Process
}

\author{
Hideo NAKAMURA and Alec MITCHELL ${ }^{1)}$
}

Formerly Department of Metals and Materials Engineering, University of British Columbia. Now at Steel Research Center, NKK Croporation, Minamiwatarida-cho, Kawasaki-ku, Kawasaki, Kanagawa-ken, 210 Japan. and Materials Engineering, University of British Columbia, Vancouver, B. C., Canada, V6T 1W5.

1) Department of Metals

(Received on November 20, 1991; accepted in final form on January 24, 1992)

In order to clarify the quantitative effect of the beam oscillation rate on the Al evaporation behavior, small amounts of $\mathrm{Ti}-6 \mathrm{Al}-4 \mathrm{~V}$ alloy were melted in a $30 \mathrm{~kW}$ EB furnace. The changes in the temperature on the melt surface, the weight loss and the Al concentration were investigated in this study.

On the basis of the experimental results, a two dimensional unsteady state heat and mass transfer model was developed. The model was used to evaluate the effect of the beam oscillation rate on the temperature behavior and the evaporation reaction during EB process and also discussion was made on the optimum beam scanning rate.

It was clearly shown that the evaporative loss of both $\mathrm{Ti}$ and $\mathrm{Al}$ could be suppressed by the increase of the beam oscillation rate. With the beam oscillation rate at more than $1.0 \mathrm{~Hz}$, however, this effect could not be observed clearly anymore. Therefore, the optimum beam oscillation rate can be considered to be in the range of $1.0-10.0 \mathrm{~Hz}$.

KEY WORDS: EB melting; Al evaporation; Ti alloys; beam oscillation rate.

\section{Introduction}

In order to avoid overheating the metal, which sometimes causes a substantial evaporative loss of valuable elements, the beam scanning technique is employed in the normal EB melting process. ${ }^{1)}$ From an operational point of view, the effect of this technique has been well confirmed empirically. However, due to the lack of fundamental studies ${ }^{2-8)}$ on EB melting process, very little is known on the optimum beam oscillation rate.

The problem dealing with the process in which heat is supplied from one or more moving heat sources as in the present case is referred as "Moving Heat Source Problem". Many studies have been made to data particularly in the field of welding metallurgy, ${ }^{9-12}$ ) where various kinds of heat sources such as gas arc, electron beam, plasma gas, and laser are used for joining materials.

Although the basic idea can be applied to the heat analysis in the EB melting processes, there are two major differences between two processes. First, the velocity of the heat source in the EB melting process is much higher than that employed in the welding processes. Second, since the whole metal is molten state in the EB melting processes, the radiation and evaporation heat loss cannot be neglected.

Because of the above reasons, neither the analytical nor the numerical treatment developed in the field of the welding processes can be applied directly to the present case

The objective of this study is, therefore, to investigate the effect of the beam oscillation rate on the evaporation behavior of alloying elements by developing an unsteady state heat and mass transfer model on the basis of experimental results.

\section{Experimental Procedure and Results}

\subsection{Experimental Procedure}

Figure 1 shows a schematic diagram of an EB furnace used in this study. The nominal power is $30 \mathrm{~kW}$ when the accelerating voltage is $20 \mathrm{kV}$. Various beam trajectories, or beam patterns can be obtained by controlling the strength of the magnetic field for both $\mathrm{X}$ \& Y directions.

Two independent vacuum systems are employed in this furnace; one for the gun chamber and the other for the melt chamber. The vacuum achieved by this system is $<1 \times 10^{-5}$ Torr for the gun chamber and $<5 \times 10^{-5}$ Torr for the melt chamber.

Water flow rate in a water-cooled copper mold is approximately $30 \mathrm{l} / \mathrm{min}$. Two thermometers monitoring the inlet and outlet water temperature are used in order to estimate the heat loss through the mold during melting.

Figure 2 shows a schematic diagram of the temperature measurement set-up. An infrared optical pyrometer is used for the in-situ temperature measurement of the molten metal. A special set-up is installed to protect the 


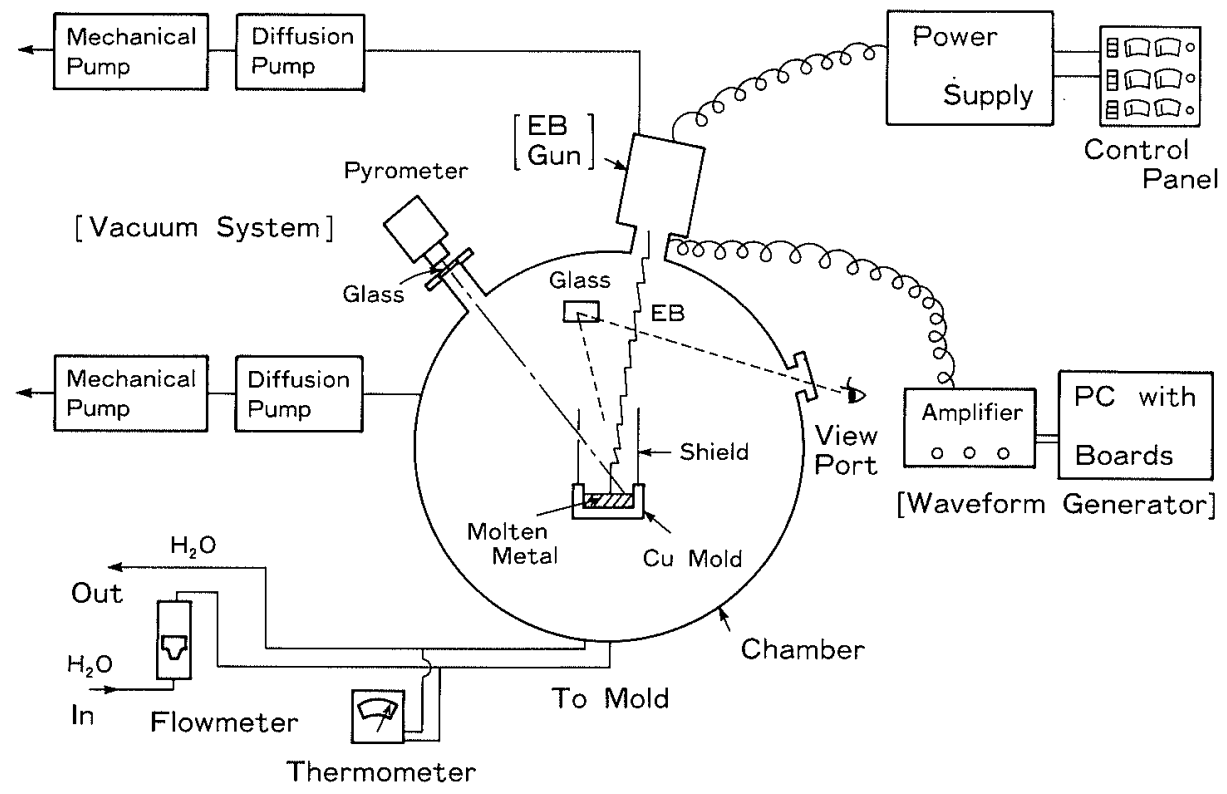

Fig. 1.

Schematic diagram of experimental apparatus.

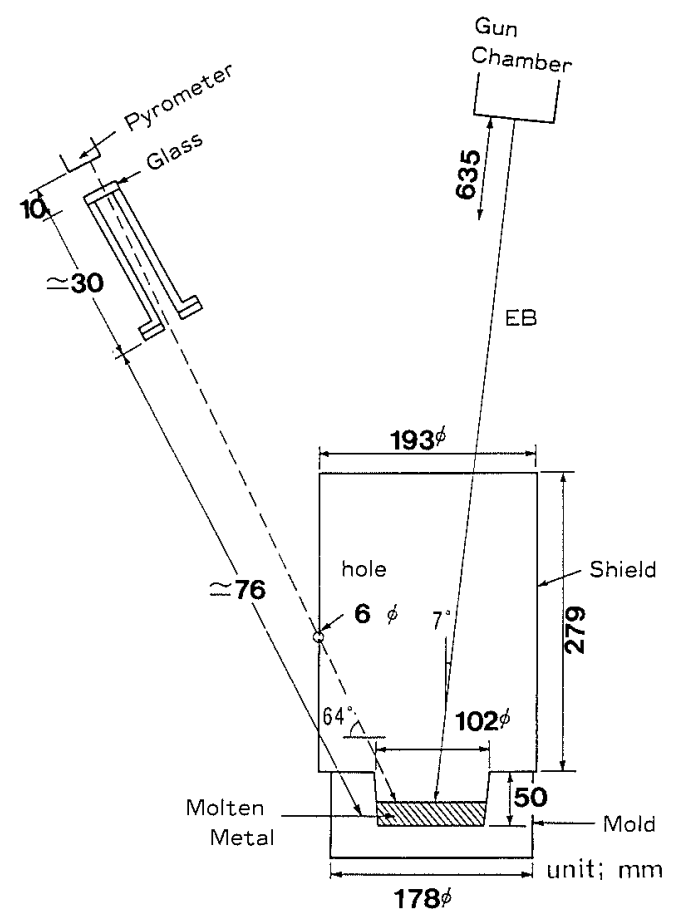

Fig. 2. Schematic diagram of in-situ temperature measurement system.

window glass from being coated during evaporation of the metal. A cylindrical shield is placed on the mold to condense the metal vapor on an inner wall. The observation site is adjusted to be approximately $3 \mathrm{~cm}$ from the center of the melt surface. The $\mathrm{mV}$ output from the pyrometer was recorded for temperature analysis.

Table 1 shows the experimental conditions used in this study. Pure $\mathrm{Ti}$ or $\mathrm{Ti}-6 \mathrm{Al}-4 \mathrm{~V}$ alloy $(600-800 \mathrm{~g})$ samples were cut from a large ingot and placed in the mold. After a determined preheating and premelting period at approximately $2 \mathrm{~kW}$, the power was raised to $15.5 \mathrm{~kW}$ as quickly as possible. Beam oscillation rates chosen were $0,0.1,1.0$ and $10.0 \mathrm{~Hz}$. In the case of the $0 \mathrm{~Hz}$ experiment the beam was set to the center of the
Table 1. Experimental conditions

\begin{tabular}{ll}
\hline EB power & $15.5 \mathrm{~kW}(18 \mathrm{kV}-0.86 \mathrm{~A})$ \\
Beam travelling radius & $1.5 \mathrm{~cm}$ \\
Frequency & $0,0.1,1,10 \mathrm{~Hz}$ \\
Time & $0^{\prime}, 1^{\prime}, 5^{\prime}, 10^{\prime}$ \\
\hline
\end{tabular}

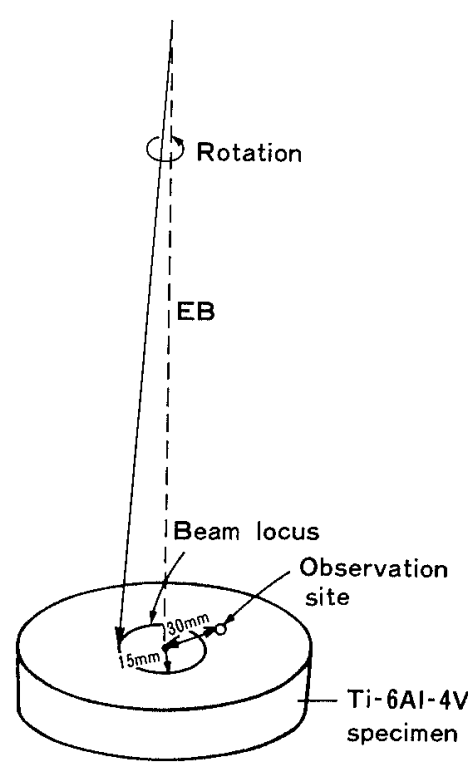

$90 \mathrm{~mm} \phi \times 25 \mathrm{mmh}$

Fig. 3. Sketch of specimen during experiment.

charged material, whereas in the case of moving beam experiments the beam traveling radius was adjusted to $1.5 \mathrm{~cm}$. Although beam spot sizes could not be measured precisely, they appeared to be $1-2 \mathrm{~mm}$ in diameter. Figure 3 shows a sketch of specimen during tests.

After a determined holding time (1,5 and $10 \mathrm{~min})$ the power was turned off. A cooling curve was obtained for each experiment in order to determine the emissivity in this system.

All samples were weighed after experiments and then sectioned, polished and analyzed for $\mathrm{Al}$ content using a SEM/EDX method, which was calibrated by using 

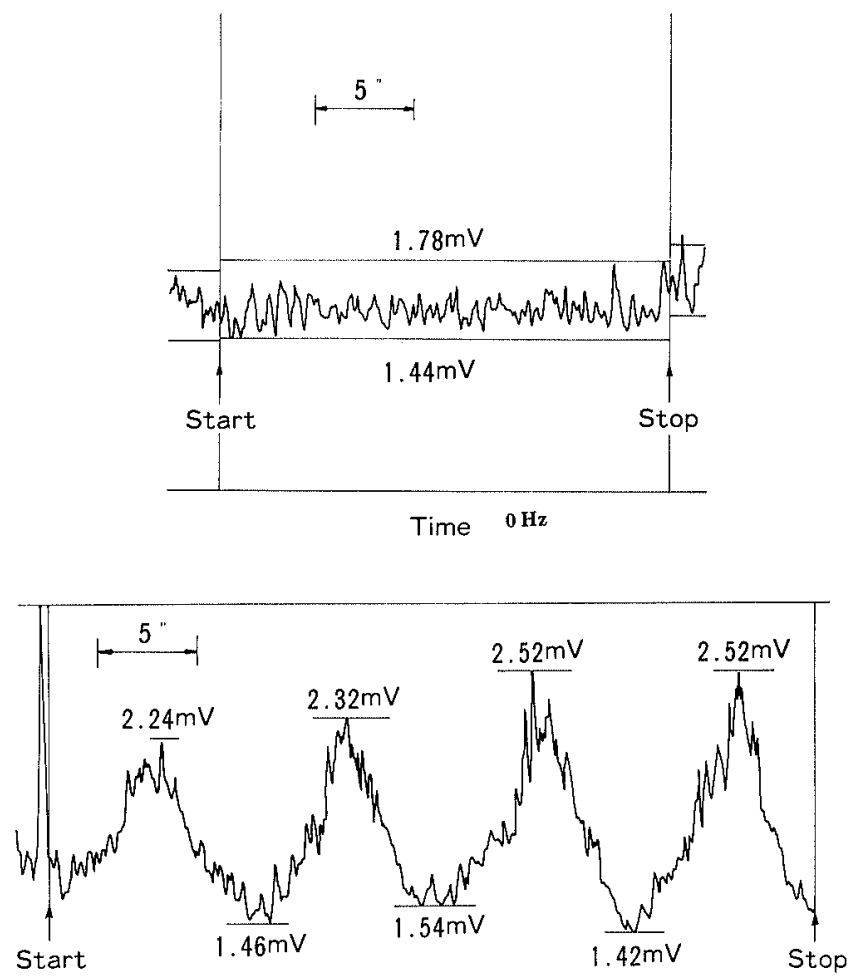

Time $\quad 0.1 \mathrm{~Hz}$
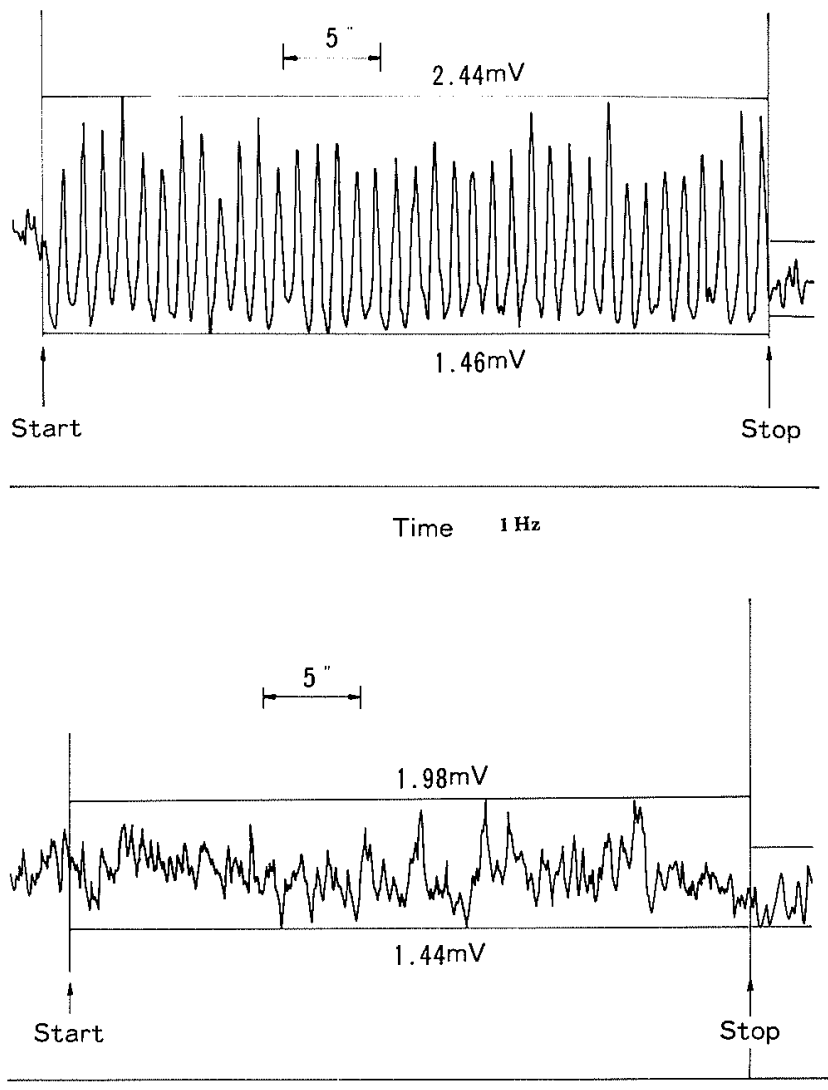

Time $\quad 10 \mathrm{~Hz}$

Fig. 4. Pyrometer outputs during experiments.

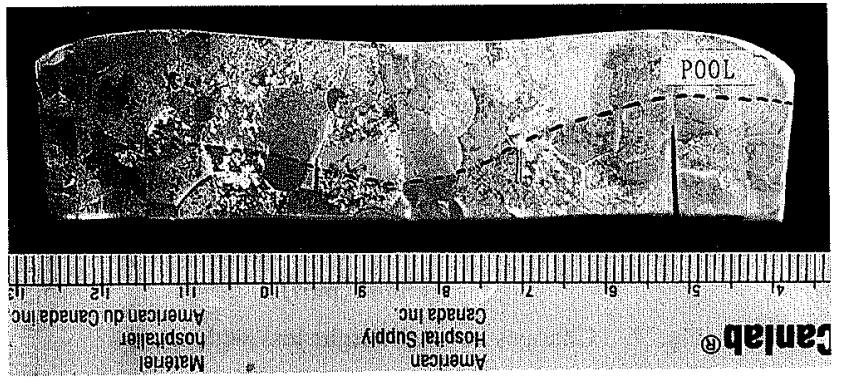

Fig. 5. Typical macrostructure of sectioned sample after experiment.

"standard samples" analyzed by emission spectroscopy. Metal which deposited on the inner wall of the shield was also analyzed.

\subsection{Experimental Results}

All results obtained in this study are shown in Table 2 .

Figure 4 shows typical pyrometer outputs obtained in various beam oscillation rate experiments. Temperature cycles found in 0.1 and $1.0 \mathrm{~Hz}$ experiments were 10 and $1 \mathrm{sec}$ respectively, which were in good agreement with expected time cycles. No temperature cycles were detected in the $10.0 \mathrm{~Hz}$ experiments, since time cycles were very short $(=0.1 \mathrm{sec})$.

Using liquidus of pure $\mathrm{Ti}\left(1688^{\circ} \mathrm{C}\right)$ and $\mathrm{Ti}-64$ alloy $\left(1620^{\circ} \mathrm{C}\right), \varepsilon^{\prime}$, the emissivity for the pyrometer, was evaluated from a cooling curve after each experiment. A typical $\varepsilon^{\prime}$ was in the range of $0.11-0.13$.

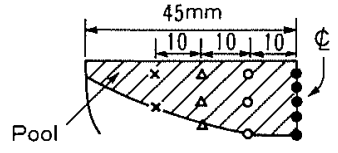

$0 \mathrm{~Hz}, 5 \mathrm{~min}$
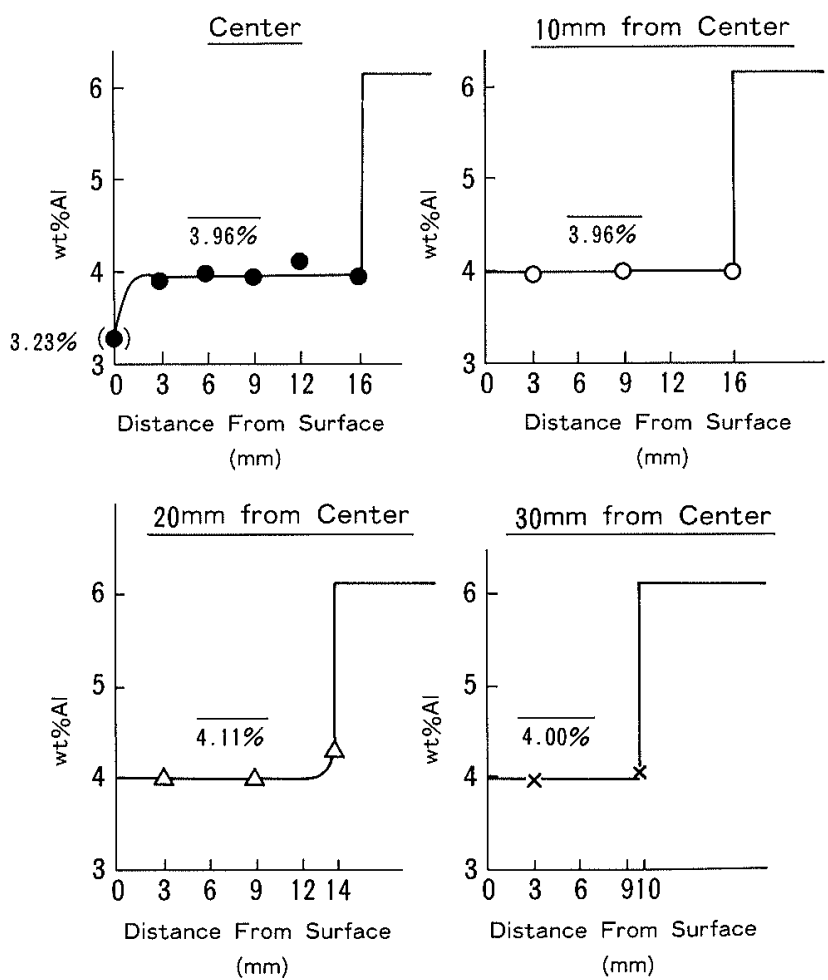

Fig. 6. Distribution of Al concentration in the pool. 


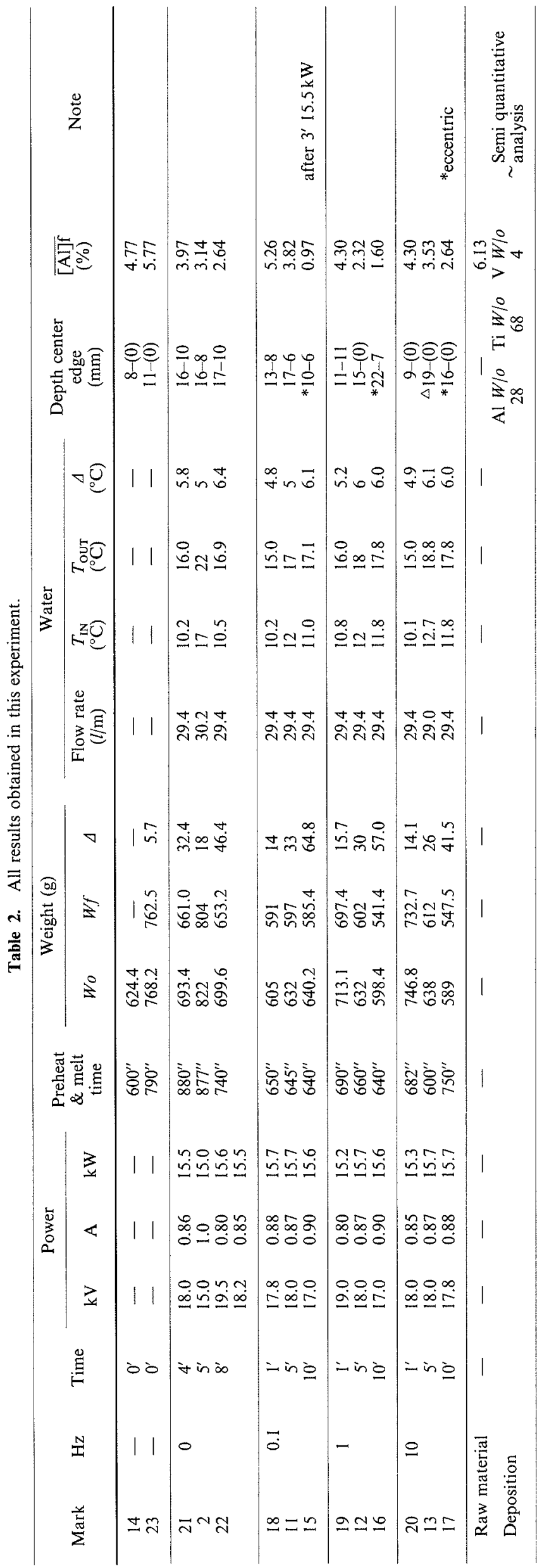

The increase in the water temperature of the mold became almost constant in 2 min for all experiments. The steady state heat transfer condition appeared to be attained after $2 \mathrm{~min}$ in the experiment.

Figure 5 shows a typical pool profile of a sample. The pool depths of the samples after 2 min were $15-17 \mathrm{~mm}$ at a center. In some samples, however, the position of the deepest pool depth was not centered because the beam could not be centered accurately. Therefore care was taken in the interpretation of these results.

Figure 6 indicates the distribution of the Al concentration in the pool obtained after 5 min experiment. As shown clearly, wt $\%$ Al was almost constant throughout in the pool. In this figure, $\mathrm{wt} \% \mathrm{Al}$ on a metal surface is also shown. There was no large difference between Al concentration on the surface (3.23\%) and that in the pool $(3.96 \%)$.

Figure 7 shows the change in the weight loss of the samples with time. The weight loss increased almost linearly with time; $40-60 \mathrm{~g}$ of the samples was lost in $10 \mathrm{~min}$. The effect of beam oscillation rate was also observed in the present experiment.

Figure 8 shows wt $\%$ Al changes with time. Al was reduced to $1-2.5 \%$ in all experimental conditions.

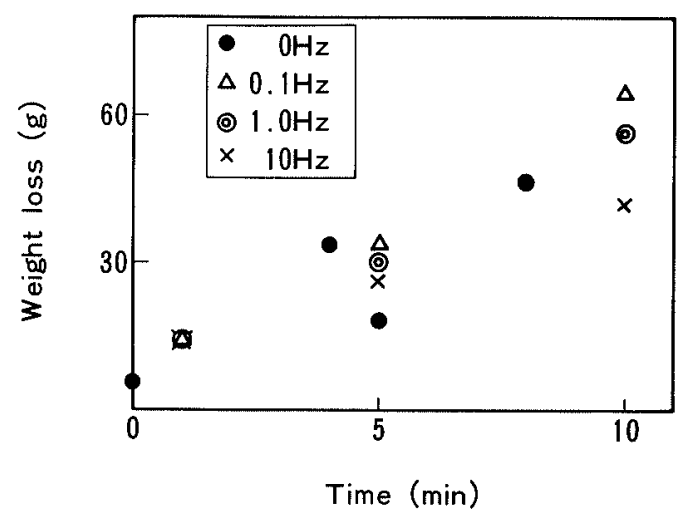

Fig. 7. Changes in total weight loss with time.

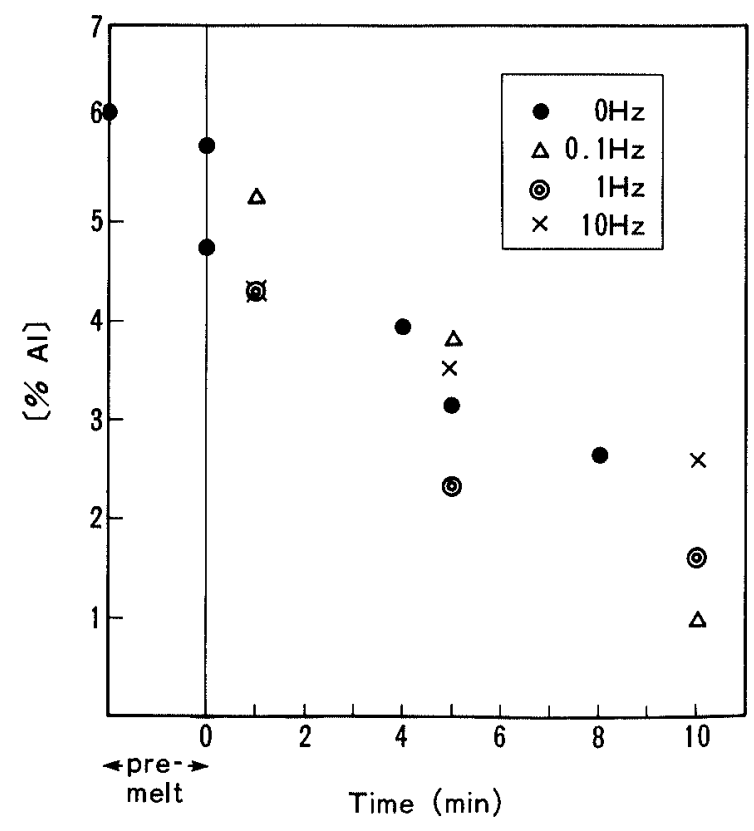

Fig. 8. Changes in Al concentration with time. 
There appeared to be no large difference between the beam oscillation rate changes as expected.

After each experiment a relatively large amount of evaporant was deposited on the inner wall of the shield. Chemical analysis of a deposit sampled after $0 \mathrm{~Hz}$ experiment is shown in Table 2. Ti also evaporated heavily along with $\mathrm{Al}$ in this experiment. The ratio of $\%(\mathrm{Ti}+\mathrm{V})$ to $\% \mathrm{Al}$ is around 2.6 .

\section{Mathematical Model}

\subsection{Basic Equation}

The shape of the molten pool observed in this study was almost identical when the beam was positioned at a center of the sample, and it can be regarded as a cylinder with approximately $9 \mathrm{~cm}$ diameter and $1.5 \mathrm{~cm}$ depth.

Since the molten pool was relatively shallow in the experiment (the ratio of diameter to depth is around 6.7) the moving beam problem can be described as a two dimensional heat flow model and the stationary beam problem as a one dimensional heat flow model.

Assuming material properties such as heat conductivity, heat capacity, and density are constant, a governing equation in a cylindrical coordinate system can be expressed as follows:

$$
\frac{1}{r} \frac{\partial}{\partial r}\left(r \frac{\partial T}{\partial r}\right)+\frac{1}{r^{2}} \frac{\partial^{2} T}{\partial \theta^{2}}+\frac{q^{\prime}}{k^{\prime}}=\frac{1}{\alpha} \frac{\partial T}{\partial t}
$$

Where, $k^{\prime}$ : Heat conductivity of Ti including the effect of molten flow (W/m K), $q^{\prime}$ : Sum of heat input and output $\left(\mathrm{W} / \mathrm{m}^{2}\right), \alpha$ : Heat diffusivity of $\mathrm{Ti}\left(\mathrm{m}^{2} / \mathrm{sec}\right)$, $\left(=k^{\prime} / C_{P} \rho\right), C_{P}$ : Heat capacity of Ti $(\mathrm{J} / \mathrm{kg} \mathrm{K})$, and $\rho$ : Density of $\mathrm{Ti}\left(\mathrm{kg} / \mathrm{m}^{3}\right)$.

A coordinate system used for the 2-D model is illustrated in Fig. 9.

In the present experiment, metal flow was observed during melting period. The driving force of the flow in this study can be considered to be a temperature gradient in the metal, which causes two flow types: 1) Natural convection flow and 2) Surface tension driven flow. ${ }^{13)}$ In order to take account of the effect of the above metal flow, a multiplying factor $F F$ was considered in the mathematical model as follows.

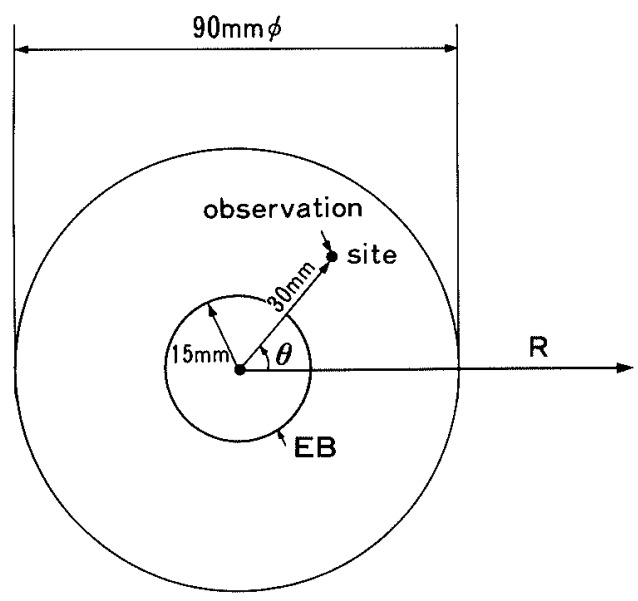

Fig. 9. Coordinate system used for 2-D model.

$$
k^{\prime}=F F k
$$

where, $k$ represents an 'ordinary' heat conductivity of $\mathrm{Ti}(\mathrm{W} / \mathrm{m} \mathrm{K})$.

$F F$ is reported to range between 7 and 10 in the case of a natural convection. ${ }^{14)}$ However, no reports have been given yet when both natural convection flow and surface tension driven flow take place.

$q^{\prime}$ in Eq. (1) is represented by Eq. (3).

$$
q^{\prime}=q^{\mathrm{EB}}-q^{\mathrm{R}}-q^{\mathrm{EV}}
$$

Where, $q^{\mathrm{EB}}$ : Total power input of $\mathrm{EB}\left(\mathrm{W} / \mathrm{m}^{2}\right), q^{\mathrm{R}}$ : Radiation heat loss $\left(\mathrm{W} / \mathrm{m}^{2}\right)$, and $q^{\mathrm{EV}}$ : Evaporation heat loss $\left(\mathrm{W} / \mathrm{m}^{2}\right)$.

The energy efficiency of the EB power input for $\mathrm{Ti}$ is reported to be around $80 \%$, when beam impinges normal to the metal. ${ }^{15)}$ In the present case, where the beam impinged almost normal, 83 degrees, to the molten $\mathrm{Ti}$ alloys, the effective power input can be calculated to be $12 \mathrm{~kW}(\fallingdotseq 15.5 \mathrm{~kW} \times 0.8)$.

Radiation heat loss, $q^{\mathrm{R}}\left(\mathrm{W} / \mathrm{m}^{2}\right)$ is represented by the following equation.

$$
q^{\mathrm{R}}=\varepsilon \sigma\left(T^{4}-T_{a}^{4}\right)
$$

where, $\varepsilon$ : Emissivity of $\mathrm{Ti}^{16)} 0.4, \sigma$ : Stefan-Boltzmann constant, $5.67 \times 10^{-8}\left(\mathrm{~W} / \mathrm{m}^{2} \mathrm{~K}^{4}\right)$, and $T_{a}$ : Ambient temperature, $298 \mathrm{~K}$.

Evaporation heat loss, $q^{\mathrm{EV}}\left(\mathrm{W} / \mathrm{m}^{2}\right)$ is given as follows.

$$
q^{\mathrm{EV}}=m_{\mathrm{Ti}} \Delta H_{\mathrm{Ti}}+m_{\mathrm{A} 1} \Delta H_{\mathrm{A} 1}
$$

where, $m_{\mathrm{Ti}}, m_{\mathrm{Al}}$ : Evaporation rate of $\mathrm{Ti}$ and $\mathrm{Al}$ $\left(\mathrm{kg} / \mathrm{m}^{2} \mathrm{sec}\right)$, and $\Delta H_{\mathrm{Ti}}, \Delta H_{\mathrm{Al}}$ : Heat of evaporation of $\mathrm{Ti}$ and $\mathrm{Al}(\mathrm{kJ} / \mathrm{kg})$.

In this study the evaporation behavior of vanadium was included in that of $\mathrm{Ti}$ for simplicity because the vapor pressure of both elements is almost the same.

It is important to know the reaction control step for the estimation of the evaporation rate of the element of interest. As shown before in Fig. 6, there was no gradient in $\mathrm{Al}$ concentration in the pool. In addition, it was also found that observed $\mathrm{Al}$ evaporation behavior could not be explained reasonably well by the diffusion control model such as Machlin's model. ${ }^{17)}$ Therefore, it seems reasonable to assume that the evaporation reaction at the surface played a main role in the present experimental condition. The reason for this seems to be that the operating temperature was not very high ${ }^{18)}$ in the present experimental condition.

The evaporation rate of each element can be expressed using Langmuir equation as follows. ${ }^{19\}}$

$$
\begin{aligned}
m_{i}= & {\left[\gamma_{i} P_{i}^{\circ} M_{i} /\left(2 M_{i} \pi R T\right)\right] X_{i} } \\
& (i=\mathrm{Ti} \text { and } \mathrm{Al})
\end{aligned}
$$

where, $\gamma$ : Activity coefficient ${ }^{5)}(-), M$ : Molecular weight $(\mathrm{kg} / \mathrm{mol}), R$ : Gas constant $(=8.315 \mathrm{~J} / \mathrm{K} \mathrm{mol}), X$ : Mole fraction $(-)$, and $P^{\circ}$ : Vapor pressure of pure element $(\mathrm{Pa})$.

The vapor pressure of pure $\mathrm{Ti}$ and $\mathrm{Al}$ is given as follows ${ }^{20)}$ :

$$
P_{\mathrm{Ti}}^{\circ}=1.33 \times 10^{(-23200 / T-0.66 \log T+13.74)}
$$


ISIJ International, Vol. 32 (1992), No. 5

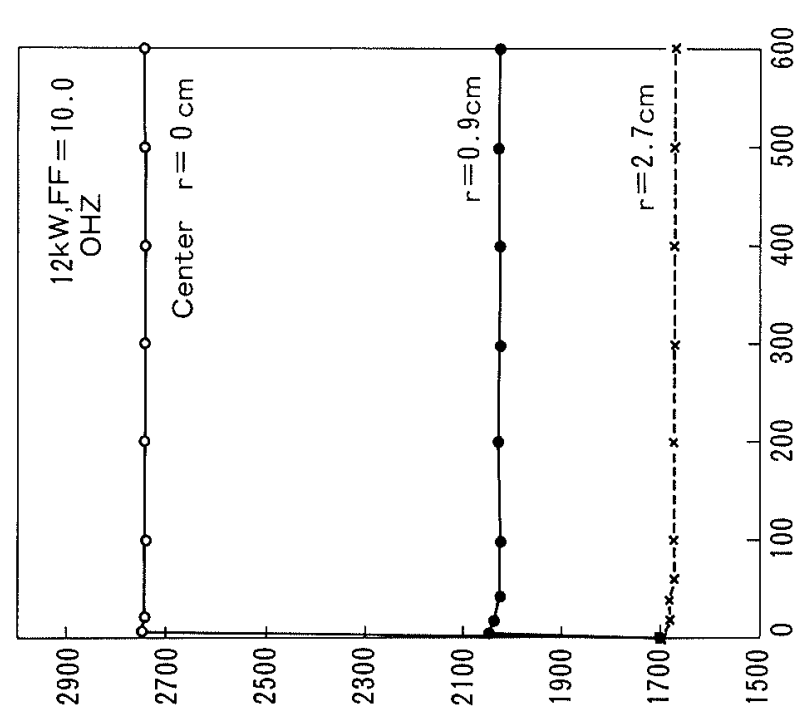

$\left(\supset_{0}\right) \cdot d \omega \partial_{\perp}$

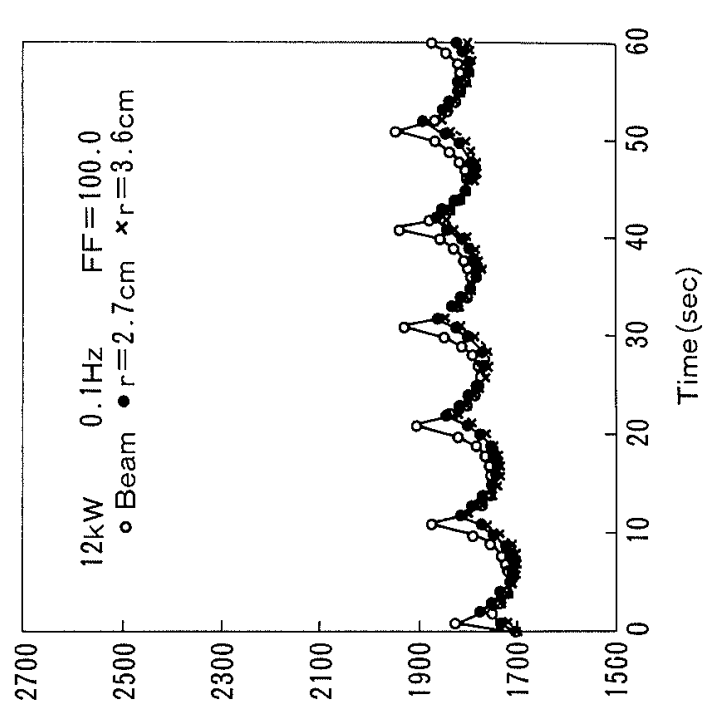

$\left(O_{0}\right) \cdot d u \partial_{\perp}$

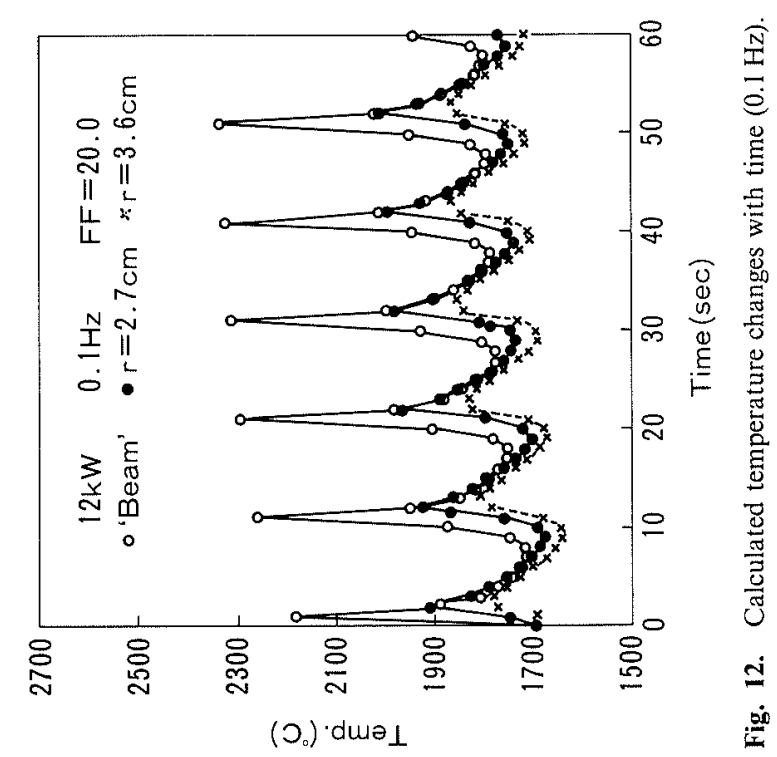

$\left(O_{0}\right) \cdot d u \partial \perp$

$\dot{\square}$

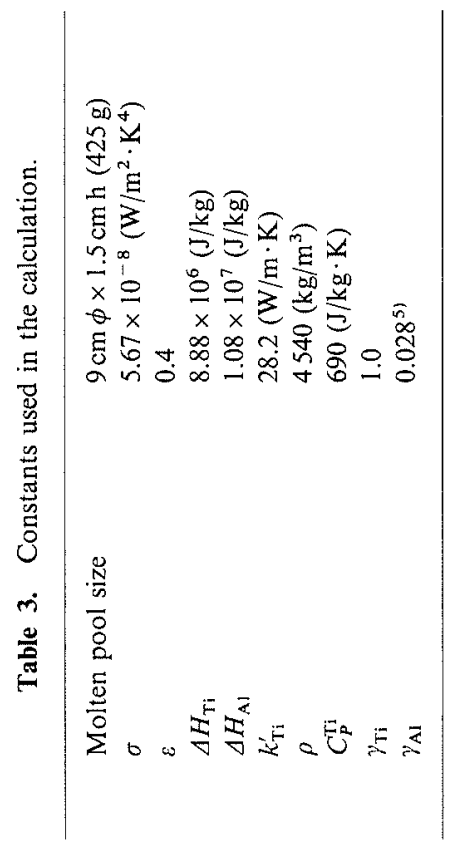

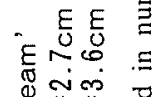

๓ஸा

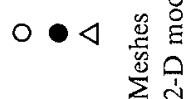

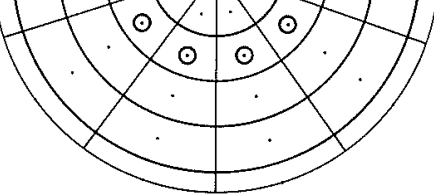

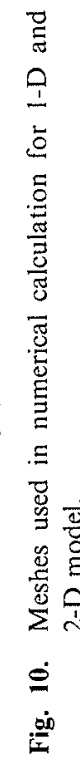

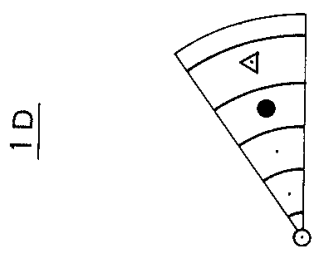

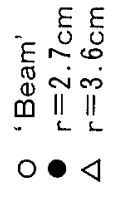

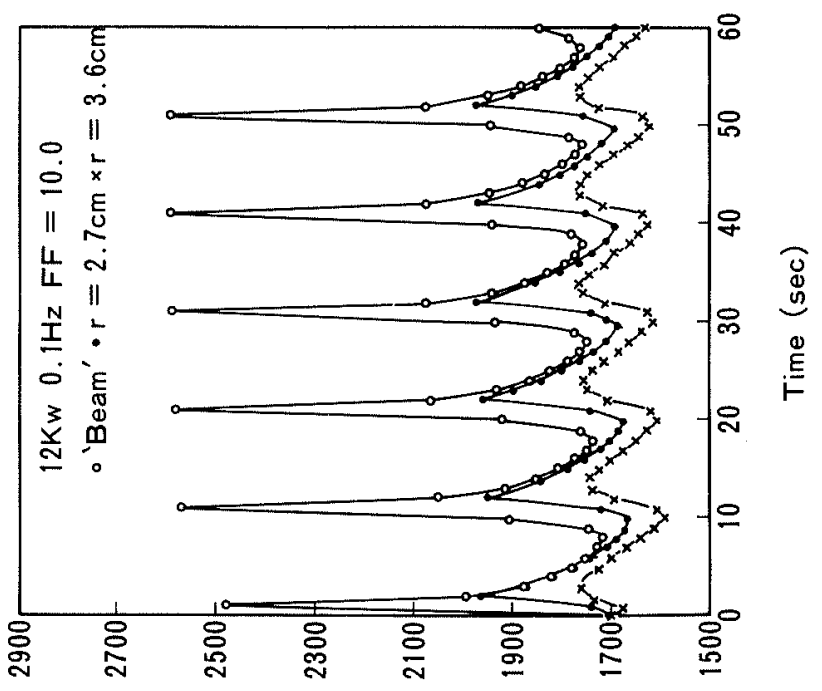

(ว) dur $\perp$ 


$$
P_{\mathrm{A} 1}^{\circ}=1.33 \times 10^{(-16380 / T-\log T+14.32)}
$$

Constants used in the calculation are summarized in Table 3.

Heat loss through a mold, which gives a boundary condition, was calculated by using the temperature increase in the cooling water of the mold obtained in the experiment.

Equation (1) was solved by a numerical method. The finite difference method (explicit method) was used for calculation.

Meshes used are shown in Fig. 10. In this figure 'Beam' indicates nodes where the beam is impinged at a certain period. The temperature observation site corresponds to either nodes indicated by " $r=2.7 \mathrm{~cm}$ " or " $r=3.6 \mathrm{~cm}$ ". The initial temperature was taken as $1700^{\circ} \mathrm{C}$ for all nodes in this calculation.

\subsection{Results and Discussion}

Figure 11 shows a calculated result of the stationary beam case at $F F=10.0$. A steady state can be achieved in a very short time. While the temperature at the beam hot spot reaches approximately $2750^{\circ} \mathrm{C}$, the temperature at $2.7 \mathrm{~cm}$ is as low as $1670^{\circ} \mathrm{C}$. A steep temperature gradient is observed.
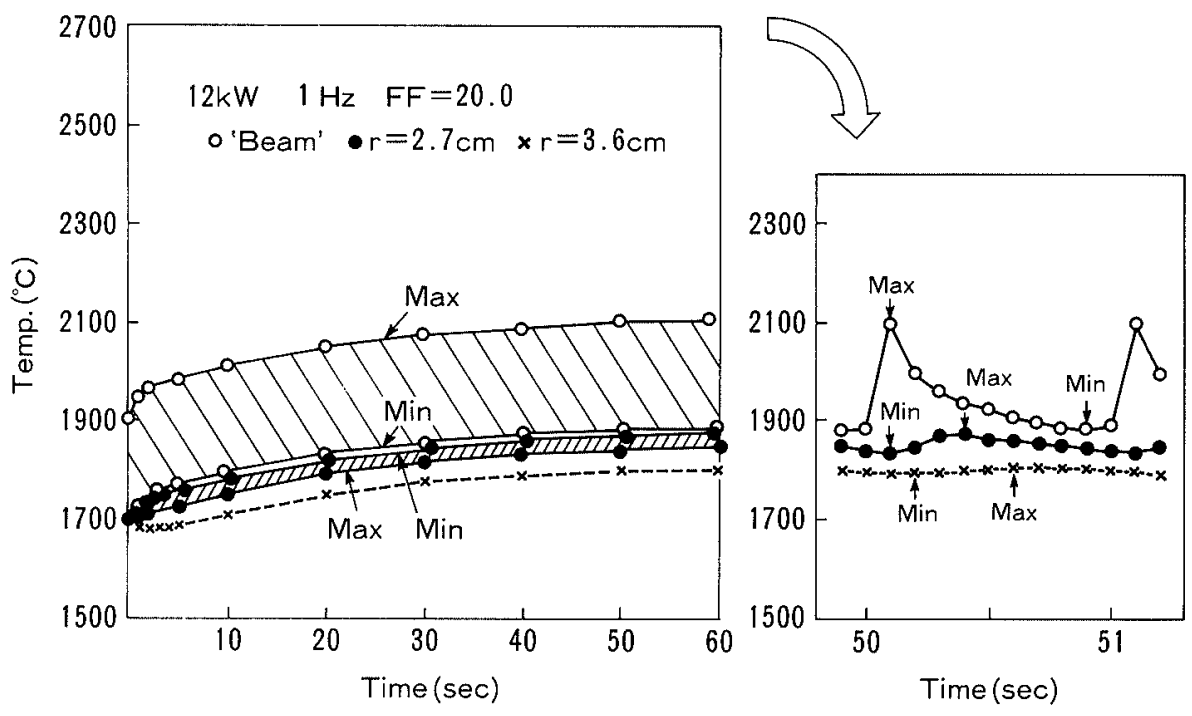

Fig. 13.

Calculated temperature changes with time $(1.0 \mathrm{~Hz})$
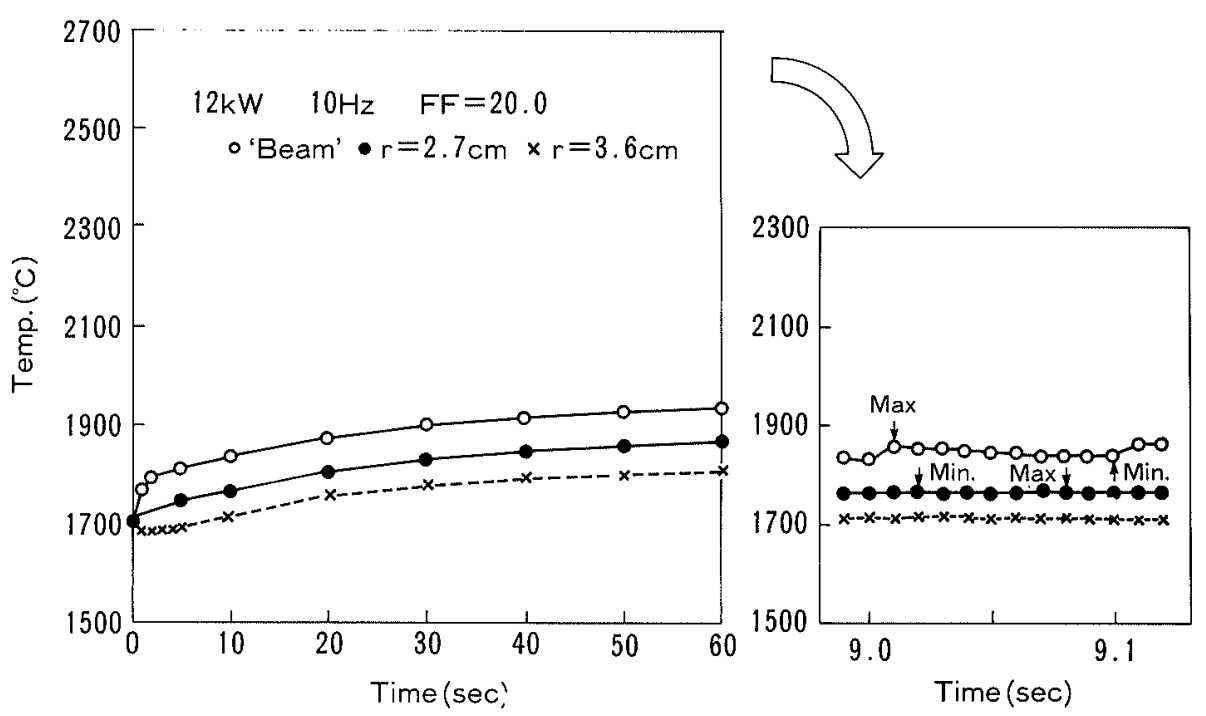

Fig. 14.

Calculated temperature changes with time $(10.0 \mathrm{~Hz})$. 


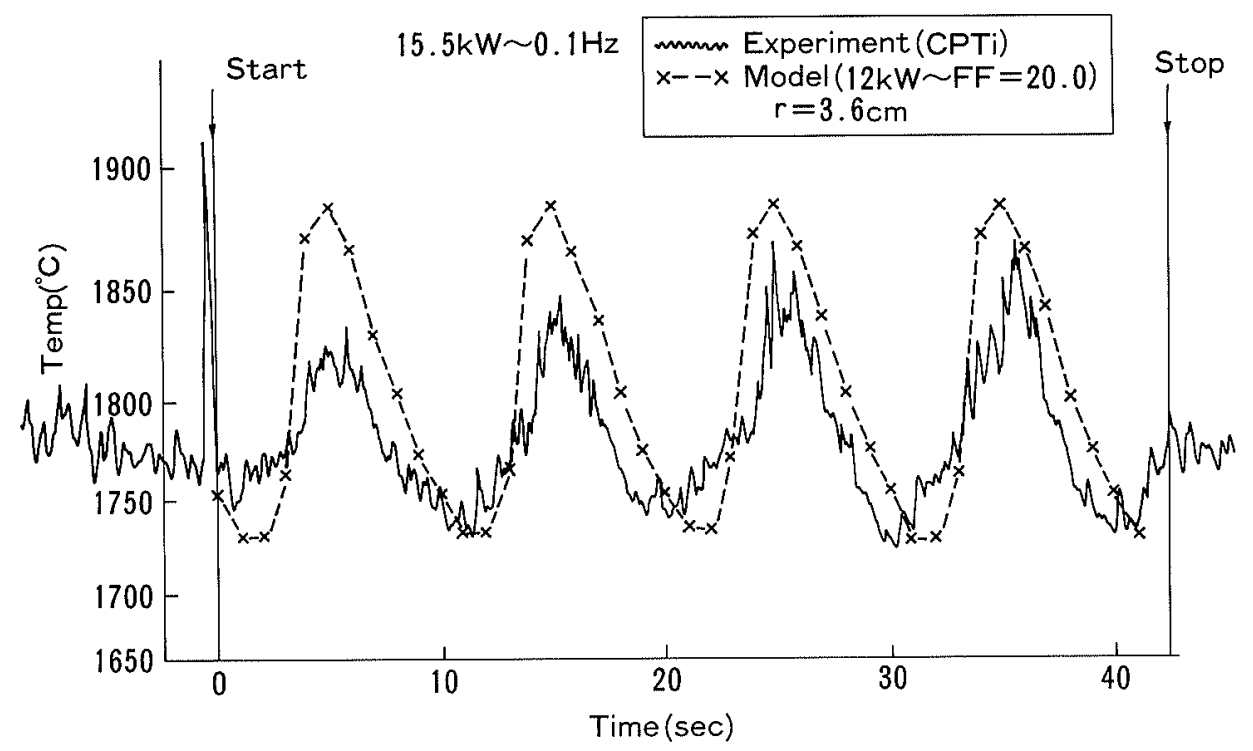

Fig. 15.

Relation between calculated and observed temperature changes with time.
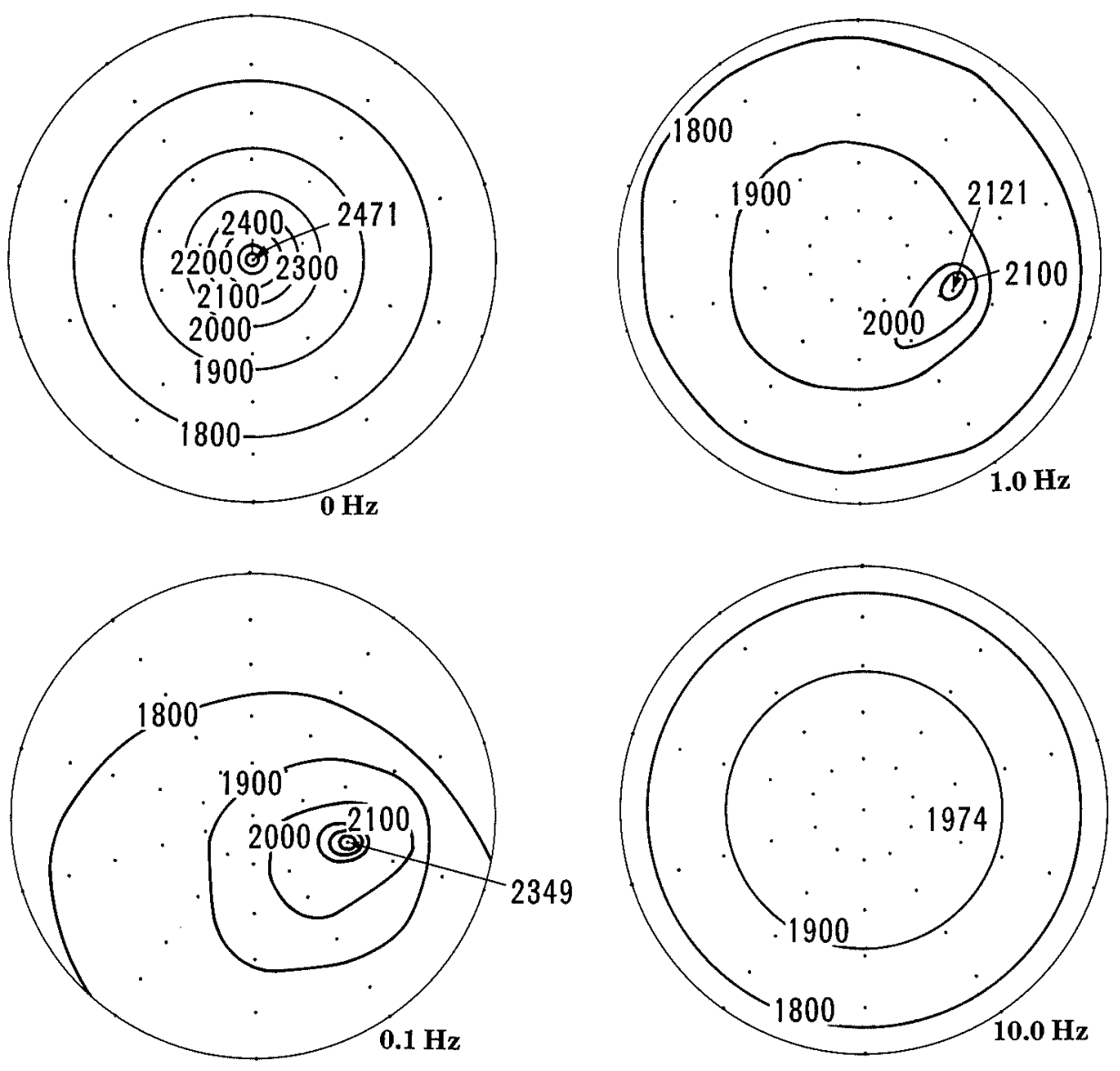

Fig. 16.

Calculated temperature contours on the melt surface at $600 \mathrm{sec}$.

compared with lower beam oscillation cases. It is clearly shown that the effect of beam oscillation rate is also large.

In order to determine the $F F$ value in this experiment, calculated temperature changes were compared with experimental results using a number of defferent $F F$ values. The best fit for these calculations was found using $F F=20$. Figure 15 shows a comparison of the temperature changes measured in the experiment (CPTi) and those calculated by the model when $F F=20$. The value of $F F=20$ is twice as much as that estimated in the case of natural convection. Considering the additional effect of the surface tension driven flow in the EB process, this might be a good estimation. This is also supported by the experimental results on the total weight loss of the samples. When $F F$ is small, for example $F F=10$, the calculated beam spot temperature becomes higher and the total weight loss predicted by the model is much larger than that obtained in the experiment. On the other hand, when $F F$ is large, for example $F F=100$, the weight loss predicted by this model is much smaller than that obtained in the experiment. In the following calculations $F F=20$ was used. 
Figure 16 shows temperature contours under various beam oscillation rates at $600 \mathrm{sec}$, when the steady-state heat transfer condition (in terms of "time averaged") appears to be achieved. As clearly seen in this figure, there is a large difference in each temperature contour. The temperature gradient on the metal surface becomes less steep with the increase of beam oscillation rate. Particularly in the case of $10.0 \mathrm{~Hz}$, calculated temperatures in the molten metal were relatively low and a nearly concentric temperature contour was obtained. This result implies that with a higher beam oscillation rate of more than $10.0 \mathrm{~Hz}$, the same kind of temperature contour would be obtained and the effect of the rapid beam scanning would not be anticipated anymore. From this calculation, it is well confirmed that overheating of molten metals can be avoided to a considerable extent by beam scanning.

The calculated total weight loss of $\mathrm{Ti}$ and $\mathrm{Al}$ with time is shown in Fig. 17. In the same figure, experimental results obtained are also shown. The total weight loss at each time was calculated by subtracting $5.7 \mathrm{~g}$, which corresponds to a weight loss at $0 \mathrm{~min}$, from the weight loss originally measured after each experiment. By comparing the calculated results with the experimental ones, it was confirmed that the tendency of the change in the total weight loss obtained in the experiment can be explained reasonably well by the model.

Figure 18 shows a relation between the calculated total weight loss and the beam oscillation rate (or beam frequency) at 5 and $10 \mathrm{~min}$. In this figure, the weight

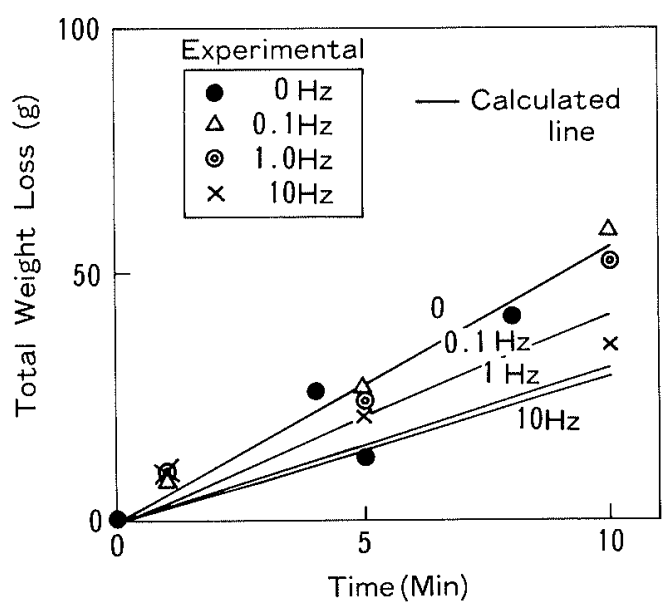

Fig. 17. Calculated change in the total weight loss with time. loss of $\mathrm{Al}$ and that of $\mathrm{Ti}$ are illustrated individually. As clearly seen, Ti evaporates substantially as well as $\mathrm{Al}$. This is attributed to the fact that Ti has large $X$ and $\gamma$ in Eq. (6) in spite of the lower vapor pressure. The ratio of the weight loss of $\mathrm{Ti}$ to that of $\mathrm{Al}$ is in the range of $1-4$. This agrees well with the experimental result, $(\mathrm{wt} \% \mathrm{Ti}+\mathrm{wt} \% \mathrm{~V}) /(\mathrm{wt} \% \mathrm{Al})=2.6$, which was obtained by the analysis of the metal deposited on an inner wall of the shield after $0 \mathrm{~Hz}$ test. Another interesting point is that the effect of the beam oscillation rate becomes smaller at $1.0-10.0 \mathrm{~Hz}$. This result can be supported by the calculated temperature contours shown in Fig. 16.

Figure 19 shows calculated results of changes in $\mathrm{Al}$ concentration with time. In this figure the initial wt $\%$ $\mathrm{Al}$ is taken as $4.5 \%$, since at "time" $=0.0$, wt $\% \mathrm{Al}$ must have decreased from the initial concentration, $6.1 \%$, due to the evaporative loss during a premelting period. As clearly seen in this figure, the model can explain the experimental results relatively well. The calculated results reveal that $\mathrm{Al}$ concentration decreases almost linearly with time. Although the decrease in the $\mathrm{wt} \% \mathrm{Al}$ can be suppressed slightly with the increase of the beam oscillation rate, the difference among beam oscillation rates is very small. This is because the relatively large evaporative loss of $\mathrm{Ti}$, as shown previously, makes the apparent change in the $\mathrm{Al}$ concentration expressed by $\mathrm{wt} \%$ smaller.

Figure 20 shows a comparison of the experimental and the calculated $\mathrm{Al}$ concentration at $5 \mathrm{~min}$. $\mathrm{wt} \% \mathrm{Al}$ at $5 \mathrm{~min}$ was calculated to be almost constant, around $3.4 \%$, regardless of the difference in the beam oscillation rate.

Although many assumptions were included in this mathematical model, the experimental results such as the change in the melt temperature, the total weight loss and $\mathrm{Al}$ evaporation behavior were reasonably well explained.

From this model it was found that the decrease in wt $\% \mathrm{Al}$ cannot be reduced by the increase of the beam oscillation rate substantially. However, the total weight loss during melting process can be suppressed by the increase of the beam oscillation rate. From an operational point of view, this is very important to prevent the deposition of the evaporant on a inner wall of the chamber, which makes the yield low. However, at beam oscillation rates over $10.0 \mathrm{~Hz}$ this effect cannot be expected.

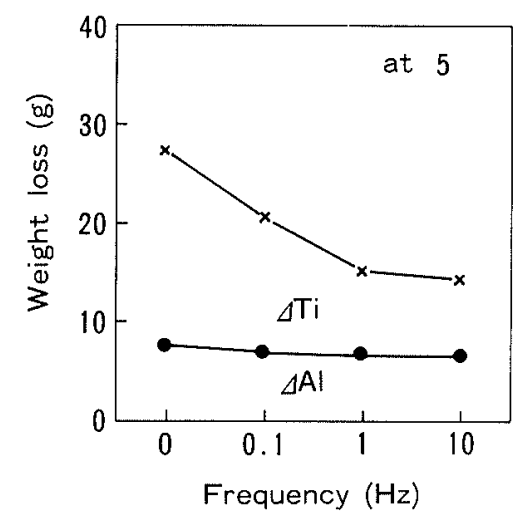

Fig. 18.

Effect of beam oscillation rate on the total weight loss at $5 \mathrm{~min}$ and $10 \mathrm{~min}$. 


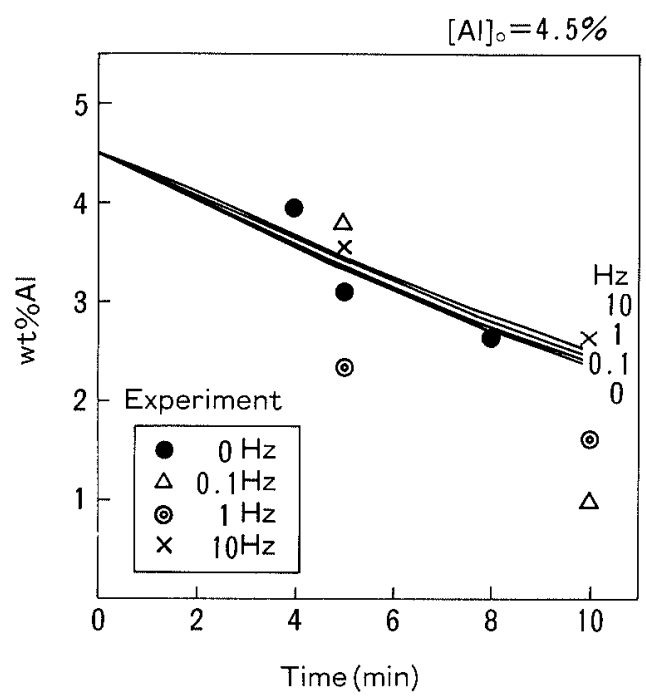

Fig. 19. Calculated changes in wt $\% \mathrm{Al}$ with time when initial Al concentration is taken as $4.5 \%$.

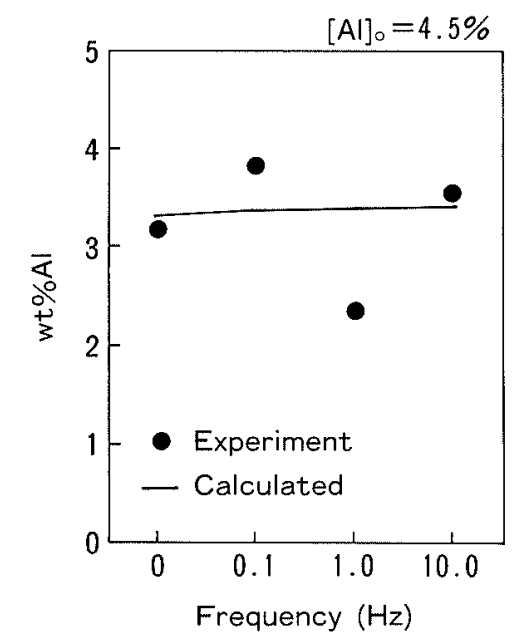

Fig. 20. Comparison between calculated and observed Al concentration at $5 \mathrm{~min}$.

\section{Conclusions}

In this study, investigation on the optimum beam oscillation rate was carried out by developing a mathematical model on the basis of a small scale EB melting experiment.

Small amounts of Ti- $6 \mathrm{Al}-4 \mathrm{~V}$ alloy were melted in a $30 \mathrm{~kW}$ EB melting furnace. The beam oscillation rates used in this study were $0,0.1,1.0$ and $10.0 \mathrm{~Hz}$. The temperature cycle observed in this study was found to be in good agreement with the given beam oscillation rate. In all samples, a significant amount of the wt $\%$ $\mathrm{Al}$ decrease and the total weight loss $(\mathrm{Al}+\mathrm{Ti})$ were observed. The effect of the beam oscillation rate was found in the total weight loss change, but could not be found clearly in the $\mathrm{wt} \% \mathrm{Al}$ decrease in the present experiment.

Based on the results from the experiment, in particular the results of the temperature measurement, 2-D and 1-D unsteady heat transfer models were made: a
2-D model for the moving beam problem and a 1-D model for the stationary beam problem. In these models, the mass balance with respect to both $\mathrm{Al}$ and Ti was also taken into account by assuming that the evaporation reaction at the interface plays a major role. From a comparison of the calculated and experimental results, $F F=20.0$, a factor considering the effect of the molten metal flow, appeared to explain the experimental results reasonably well under the present experimental conditions.

According to this model, it was clearly shown that the evaporative loss of both $\mathrm{Al}$ and $\mathrm{Ti}$ could be suppressed by increasing the beam oscillation rate up to around $1.0 \mathrm{~Hz}$. This result was obtained because the overheating of the molten metal was prevented substantially. With the beam oscillation rate at more than $1.0 \mathrm{~Hz}$, however, this effect could not be found clearly anymore. On the other hand, in terms of the composition control of $\mathrm{Al}$, the effect of the beam oscillation rate was not significant, since $\mathrm{Ti}$ also evaporated simultaneously during a melting period under the low operating pressure.

In conclusion, the optimum beam oscillation rate can be considered to be in the range of $1.0-10.0 \mathrm{~Hz}$.

\section{REFERENCES}

1) D. Apelian and C. H. Entrekin: Int. Met. Rev., 31 (1986), 77.

2) T. Santala and C. A. Adams: J. Vac. Sci. Technol, 17 (1970), ss. 22.

3) Y. Nakamura and M. Kuwabara: Trans. Iron Steel. Inst. Jpn., 15 (1975), 103.

4) S. Schiller and H. Förster: Electron Beam Remelting and Refining State of the Art 1984, Proc. Conf., Bakish Materials Corporation, Englewood, NJ, (1984), 49.

5) A. Mitchell and K. Takagi: Proc. Vacuum Metallurgy Conf., (1984), 89.

6) J. Herbertson: Electron Beam Remelting and Refining State of the Art 1986 Part II, Proc. Conf., Bakish Materials Corporation, Englewood, NJ, (1986), 19.

7) H. S. Kheshgi and P. M. Gresho: Electron Beam Remelting and Refining State of the Art 1986 Part II, Proc. Conf., Bakish Materials Corporation, Englewood, NJ, (1986), 68.

8) D. Tripp: Master's Thesis, University of British Columbia, (1987).

9) D. Rosenthal: Trans. ASME, 43 (1946), 849.

10) For example, N. Christensen, V. Davies and K. Gjermundsen: Br. Weld. J., 12 (1965), 54.

11) T. W. Eager and N. S. Tsai: Weld. J., 62 (1983), 346s.

12) S. Kou and Y. H. Wang: Metall. Trans., 17A (1986), 2265.

13) C. R. Heiple and J. R. Roper: Weld. J., 61 (1982), $97 \mathrm{~s}$.

14) A. S. Ballantyne: Ph. D. Thesis, University of British Columbia, (1978).

15) S. Schiller, U. Heisig and S. Panzer: Electron Beam Technology, John Wiley \& Sons, Inc., New York, NY, (1982).

16) Thermal Properties of Titanium Alloys, Defense Materials Information Center, Battelle Memorial Institute, Columbus, Ohio.

17) E. S. Machlin: Trans. Met. Soc. AIME, 218 (1960), 314.

18) A. Mitchell, H. Nakamura and D. Tripp: Electron Beam Remelting and Refining State of the Art 1987, Proc. Conf., Bakish Materials Corporation, Englewood, NJ, (1987), 23.

19) G. H. Geiger and D. R. Poirier: Transport Phenomena in Metallurgy, Addison-Wesley, Readings, Mass., (1973).

20) O. Kubaschewski and C. B. Alcock: Metallurgical Thermochemistry, 5th ed., Pergamon Press, Oxford, (1979). 